\title{
Smart Headlamp Optics Design with Multi-array LEDs
}

\author{
Jin Hee $\mathrm{Yu}^{1}$, Suk Ju Ro ${ }^{1}$, Jun Ho Lee ${ }^{1 \dagger}$, Chang Kook Hwang ${ }^{2}$, and Dong Jin $\mathrm{Go}^{2}$ \\ ${ }^{1}$ Department of Optical Engineering, Kongju National University, 182 Shinkwan-dong, Kongju 314-701, Korea \\ ${ }^{2}$ SL Lighting Corporation, 887-4 Gumdan-dong, Bukgu, Daegu 702-800, Korea
}

(Received July 31, 2013; Revised manuscript October 1, 2013; Accepted October 1 2013)

\begin{abstract}
We investigated the optical design of a smart headlamp capable of producing various beam patterns through only on/off modulation of light sources. This was implemented by forming a continuous matrix of beams from discontinuous beam patterns by means of a multi-array LED optical system. As one such optical system, the multi-array LED system is a convenient and economical device for implementing beam patterns with the simple on/off modulation of the light sources. A single optical assembly module can be made by combining a multiple-LED array, optical system module, and electronic control with no need for any additional mechanical components. The present optical system was designed to include a secondary lens and a projection lens mounted at the front of each LED in the array to realize accurate lighting patterns as well as the required luminosity at a distance of $25 \mathrm{~m}$ in the forward direction. Finally, we identified and analyzed the patterns implemented by the designed optical system that produced satisfactory performance of high beams and adaptive driving beams (ADB).
\end{abstract}

Keywords: LED, Smart headlamp, Multi-array LED

OCIS codes: (220.3620) Lens system design; (220.2945) Illumination design; (120.4820) Optical systems; (230.3670) Light-emitting-diodes

\section{멀티 어레이 엘이디를 이용한 지능형 전조등 광학 설계 \\ 유진희 $^{1} \cdot$ 노석주 $^{1} \cdot$ 이준호 $^{\dagger} \cdot$ 황창국 $^{2} \cdot$ 고동진 $^{2}$ \\ ${ }^{1}$ 공주대학교 광공학과, 기하광학 연구실 \\ (ㅇ) 314-701 공주시 신관동 공주대학교 제2공학관 304호 \\ ${ }^{2}$ (주)에스엘라이팅 \\ (우 702-800 대구시 북구 검단동 $887-4$}

(2013년 7월 31일 받음, 2013년 10월 1일 수정본 받음, 2013년 10월 1일 게재 확정)

본 논문에서는 멀티 어레이 엘이디를 이용한 불연속적인 광원의 빔 패턴이 광학계만으로 연속적인 매트릭스 빔으로 형성되어 광원의 점·소등만으로 다양한 빔 패턴을 구현할 수 있는 지능형 전조등의 광학 설계를 연구하였다. 기존 지능형 전조등의 기술과 다르게 멀티 어레이 엘이디를 이용한 지능형 전조등은 다수의 광원 엘이디와 하나의 광학계 어셈블리 모듈 구성으로 전자 제어 를 통해 별도의 기구적인 작동 없이 빔 패턴을 변화시킬 수 있다. 본 연구에서 광학 설계는 상향등과 자동 조정 주행등의 패턴 구현과 광도 값을 만족시키기 위해 LED 앞 단에 2차렌즈 설계와 측벽 설계, 투사렌즈 설계를 실시하였다. 그 결과 불연속적인 광원의 패턴이 광학계를 통해 전방 $25 \mathrm{~m}$ 에서 14 개의 동일한 사이즈와 밝기를 갖는 셀들이 모여 연속적인 하나의 매트릭스 빔 패턴을 형성하는 설계 조건을 만족하였다. 또한 설계된 광학계의 제작 및 측정을 통해 상향등의 원거리 시인성을 위한 최대 $45000 \mathrm{~cd}$ 이상의 배광 법규 조건을 약 $50000 \mathrm{~cd}$ 로 만족하였고, 자동 조정 주행 빔 패턴 구현 시 광원의 소등 영역이 $0.32 \mathrm{~lx}$ 로 측정되어 배광 법규 $0.4 \mathrm{~lx}$ 이하를 만족하였다.

Keywords: 엘이디, 지능형 전조등, 멀티 어레이 엘이디

OCIS codes: (220.3620) Lens system design; (220.2945) Illumination design; (120.4820) Optical systems; (230.3670) Light-emitting-diodes

\footnotetext{
${ }^{\dagger}$ E-mail: jhlsat@kongju.ac.kr

Color versions of one or more of the figures in this paper are available online.
} 


\section{I. 서 론}

어두운 환경에서 주로 사용되는 전조등은 운전자에게 없어 서는 안 되는 기본적인 조명수단이다. ${ }^{[1]}$ 그래서 야간에 운전 자는 고정되어 있는 전조등의 빛 조사방향 때문에 가로등이 없는 어두운 도로 환경에서 갑자기 마주하게 되는 보행자나 물체로 인해 능동적으로 대처하는데 어려움을 겪는 경험을 한번쯤 가지고 있을 것이다. 그래서 최근에는 자동차 전조등 에 기술을 접목하여 좋은 시인성 확보와 운전자, 보행자의 안전성을 높일 수 있는 개발이 활발하게 이루어지고 있다. ${ }^{[1]}$

자동차의 광원은 과거에 단지 조명으로만 여겨졌다면 요즘 에는 소비전력이나, 수명, 운전자의 안전성 등을 고려한 광 원들로 대체되고 있다. 전조등의 광원은 1970년대 이전에는 백열 전조등(Incandescent Headlamp)으로 사용되었지만 전구 의 수명이 짧고, 전조등의 조명성능에 한계가 있다는 이유로 오늘날에는 거의 사용되지 않고 있다. ${ }^{[2]}$ 그 뒤를 이어 할로겐 전조등(Halogen Headlamp)이 개발되었고, 반사경의 설계방 법에 따라 다양하게 나뉘며 백열전구보다 에너지 효율성이 높고 긴 수명을 가진 장점 때문에 스폿 조명으로 사용되는 박물관이나 미술관, 전시용 조명으로 많이 사용되고 있다. ${ }^{[3]}$ 그리고 일명 $\mathrm{HID}$ (High Intensity Discharge)이라 불리는 가스 방전 전조등(Xenon Headlamp)은 높은 광원 효율로 현재에도 많이 사용되고 있는 광원 중의 하나이다. 하지만 근래에는 친환경 광원으로 $\mathrm{LED(Light} \mathrm{Emitting} \mathrm{Diode)의} \mathrm{사용량이} \mathrm{증}$ 가하면서 자동차 전조등으로 각광을 받고 있다. 타 광원과는 달리 순간 점등이 가능하고 최고 휘도를 바로 낼 수 있으며, 태양광에 가까운 색 온도를 갖기 때문에 빛이 조사되는 부분 의 주변부를 어둡게 느끼는 현상이 적어 안정성에서 좋은 평 판을 받고 있다. ${ }^{[4]}$ 광원으로 $\mathrm{LED}$ 의 적용 영역이 확대되면서 지능형 전조등의 기술 개발 시 대항차에게 눈부심을 주지 않 으면서 선명한 빔 패턴을 형성하는 새로운 광학계의 개발이 요구된다. ${ }^{[5]}$

따라서 본 논문에서는 별도의 기구적인 작동 없이 불연속 적인 광원의 빔 패턴을 광원의 나열과 하나의 광학 어셈블리 모듈만으로 다양한 빔 패턴을 연속적으로 구현할 수 있는 멀 티 어레이 엘이디를 이용한 지능형 전조등의 광학 설계를 실 시하고, 설계된 광학계의 시뮬레이션과 제작 및 측정을 통해 빔 패턴을 구현하고 분석하였다.

\section{II. 기술적 배경}

\section{1. 지능형 전조등 신기술}

지능형 전조등(Smart headlamp)이란 단순히 빛을 비추는 기능을 넘어 지능을 가지고 스스로 상황을 판단해 자동으로 빛을 바꾸어주는 시스템과 결합된 전조등이다.

그림 1 은 원거리 조명으로 사용되는 상향등의 신기술로써 상대방 차의 눈부심을 주어 불쾌감을 느끼는 문제점을 보안 하여 개발된 Glare Free High Beam, $\mathrm{ADB}$ (Adaptive Driving Beam)이다. 그림 1(a)는 Glare Free High Beam으로 주행 중
에도 상향등을 계속 구현하면서 밝기 차이를 주어 눈부심을 감소시켜주는 기능이며, 그림 $1(\mathrm{~b})$ 의 $\mathrm{ADB}$ 패턴은 대항차의 영역을 감지하여 자동적으로 소등을 통해 패턴을 조절해주 는 기술이다. ${ }^{[6,7]}$

또한 그림 2 는 보통 평상시 주행용으로 사용되는 하향등으 로 주변환경이나 도로의 곡률의 사용조건에 따라 자동으로 빔 패턴을 바꾸어주는 AFLS(Adaptive Front Light System), ACOL(Adaptive Cut-off Line)이다. 그림 2(a)의 AFLS 기능 의 경우 교차로, 도심지와 같은 환경에 운전자가 마주하게 되면 빔의 밝기와 패턴이 자동으로 바뀌며, 그림 2(b) ACOL 는 거리에 따라 대항차의 빔 밝기 차이를 주는 기술이다. ${ }^{[8]}$

지능형 전조등의 램프 기술들은 현재 국내, 국외에서 주로 고급 차량에 일부만 적용되고 있다. 하지만 이러한 빔 패턴 기능들은 셔터를 이용하여 패턴을 변화시킴으로써 여러 가 지 빔 패턴 구현이 가능하며, 셔터를 구동하기 위해서는 엑 츄에이터나 모터 등과 같은 추가적인 기계장치가 필요하다. ${ }^{[9]}$

\subsection{Multi-array $\mathrm{LED}$ 를 이용한 지능형 전조등}

Multi-array LED를 이용한 지능형 전조등의 기술은 나열된 $\mathrm{LED}$ 의 점소등만으로 가변 패턴을 구현하는 방식이기 때문 에 별도의 기구적인 작동 없이 상향등. $\mathrm{ADB}, \mathrm{AFLAS}, \mathrm{SPOT}$

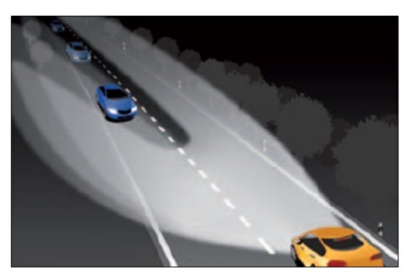

(a) Glare Free High Beam

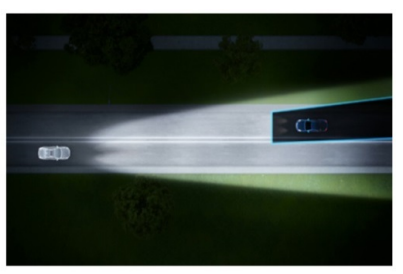

(b) $\mathrm{ADB}$ (Adaptive Driving Beam)
FIG. 1. New technology of smart headlamp high beam.

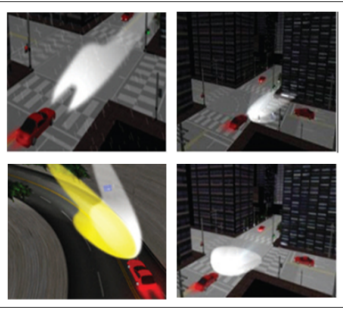

(a) AFLS(Adaptive Front Light System)

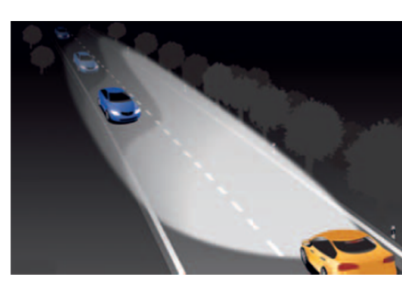

(b) ACOL (Adaptive Cut-Off Line)
FIG. 2. New technology of smart headlamp low beam.

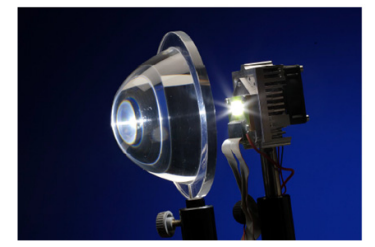

(a) Multi-array LED Smart Headlamp

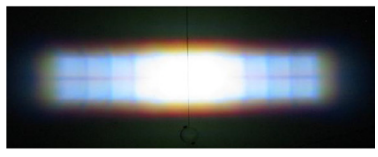

(b) Matrix Beam Pattern
FIG. 3. Configuration and beam pattern of multi-array LED headlamp. 
Light 등과 같은 다양한 빔 기능을 하나의 광학계로 나타낼 수 있는 통합형 램프 시스템이다. 전체적인 매트릭스 빔 패 턴은 하나하나의 셀 구성으로 이루어지며, LED 칩의 개별 작동이 가능하다. 또한 전자적인 제어를 통해 밝기를 조절할 수 있다. 그림 3(a)는 실제 제작된 Multi-array LED를 이용한 지능형 전조등 제품의 간단한 구성을 보여주며, 그림 3(b)는 Multi-array LED 기법으로 구현된 매트릭스 빔 패턴의 형상 을 예시로 보여주고 있다. ${ }^{[10]}$

\section{III. 설계 및 분석}

Multi-array LED 지능형 전조등의 광학계 설계에 앞서 설 계 조건에 대한 분석을 실시하였다. 그림 4는 상향등과 $\mathrm{ADB}$ 패턴의 전체적인 매트릭스 빔 형상으로 실제 전방 $25 \mathrm{~m}$ 스 크린에서 보여지는 공간적 분포도이다. 그리고 표 1 는 주행 하는 운전자 시야에 만족하는 패턴의 광학 설계 요구 조건이 다. 렌즈 설계 시 렌즈 광축은 3 번을 기준으로 전방 $25 \mathrm{~m}$ 스 크린에서 14 개의 개별 셀들이 모여 하나의 매트릭스 빔으로 구현 되어야 한다. 이때 기본적으로 개별 셀의 크기는 정사 각형의 $2.5^{\circ} \times 2.5^{\circ}$ 의 $45000 \mathrm{~cd}$ 를 만족해야 한다. 그리고 외곽 부로 갈수록 개별적인 전기 제어를 통해 패턴이 서서히 옅어 지는 형상이 구현되어야 한다. 그 이유는 패턴의 뚜렷한 외 곽선 형상보다는 운전자의 시야가 집중되는 중앙은 밝고 패 턴의 외곽부로 갈수록 자연스럽게 옅어지는 패턴을 구현함 으로써 운전자의 시야가 중앙으로 집중될 수 있게 도와주고, 시인성을 높일 수 있기 때문이다. 또한 LED 하나의 발광면

Vertical

Lens axis (center)

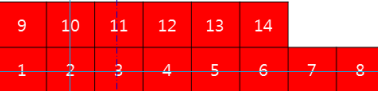

Horizontal

FIG. 4. Spatial distribution map of multi-array LED beam pattern.

TABLE 1. Optical design requirement of multi-array LED smart headlamp

\begin{tabular}{c|c}
\hline \hline \multicolumn{2}{c}{ Optical Design Requirement } \\
\hline Pattern Composition & 14 Chip \\
\hline Total Pattern Size (Lens axis: 3) & $16.25^{\circ} \times 5^{\circ}$ \\
\hline Pattern Size Of Individual Chip & $\left(1\right.$ Chip) $2.5^{\circ} \times 2.5^{\circ}$ \\
\hline Lens Material & PC, PMMA \\
\hline High Beam Max cd & $>45000 \mathrm{~cd}$ \\
\hline Dark zone Lux & $<0.4 \mathrm{~lx} @ 25 \mathrm{~m}$ \\
\hline LED Lumen (1 Chip) & $200 \mathrm{~lm}$ \\
\hline LED On/ Off & Individual
\end{tabular}

적은 $1 \times 1 \mathrm{~mm}^{2}$, 광속은 200 lumen의 LED를 사용하였다.

그림 5는 상향등과 $\mathrm{ADB}$ 패턴 구현을 위한 광학계 설계 컨 셉 구상도를 나타내었다. 설계 요구조건을 바탕으로 전체적 인 매트릭스 빔 패턴은 1 칩 당 $1 \times 1 \mathrm{~mm}^{2}$ 의 발광 면적을 갖 는 불연속적인 14 개의 LED 칩이 광학계를 통해 연속적으로 $2.5^{\circ} \times 2.5^{\circ}$ 의 동일한 사이즈를 만족하고 동일한 전류를 인가 했을 때 패턴의 밝기 차이가 발생하지 않으며, 암영대가 최 소화될 수 있는 광학 설계가 이루어져야 한다. 이를 바탕으 로 불연속적인 광원의 빔 패턴을 2 차렌즈 설계를 통해 연속 적인 동일한 셀 사이즈를 구현하면서, 셀 간의 밝기 차이가 발생하지 않도록 2차렌즈 주변에 빛을 차단하는 역할을 하 는 측벽 설계를 추가하였다. 그리고 2차렌즈를 통해 형성된 패턴이 전방 $25 \mathrm{~m}$ 스크린에서 연속적인 빔 패턴으로 구현될 수 있도록 투사렌즈 설계가 이루어져야 한다. 전체적인 광학 계의 설계는 조명 광학계의 2차렌즈, 측벽 설계와 결상 광학 계의 투사렌즈 설계로 나누어 진행하였다. 투사렌즈 설계는 렌즈 설계 소프트웨어인 ZEMAX, 조명 광학계의 설계와 통 합형 광학계의 시뮬레이션은 조명 설계 소프트웨어인 LightTools를 사용하였다.

\section{1. 결상 광학계 설계}

결상 광학계의 투사렌즈는 $\mathrm{LED}$ 로부터 나온 빛이 2차렌즈 통과 후 사각형 패턴으로 형성되면 전방 $25 \mathrm{~m}$ 지점에서 연 속적인 매트릭스 빔 패턴을 구현하는 동시에 수차를 제거하 여 운전자에게 보다 뚜렷한 빔 패턴을 나타낼 수 있는 역할 을 한다. 그림 6 는 설계된 투사렌즈의 형상을 보여준다. 그림

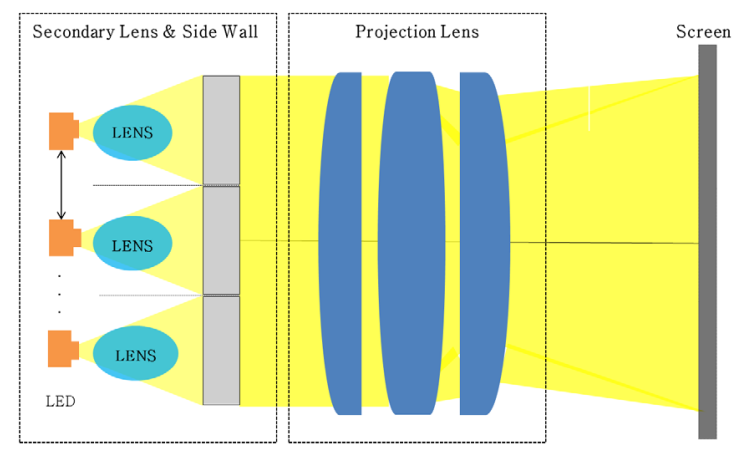

FIG. 5. Schematic of optical design.

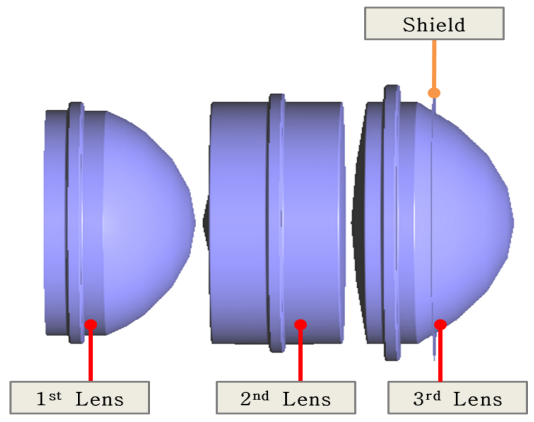

FIG. 6. Projection lens design. 
에서 1 번과 2 번렌즈는 내열성이 좋아 쉽게 변형되지 않는 Polycarbonate 재질을 사용하였고, 3번 렌즈는 PMMA 재질 을 사용함으로써 가공성까지 고려하여 모두 플라스틱 재질 을 사용하였다. 그리고 패턴 가장자리에 발생하는 글레어를 최소한으로 하기 위해 3 번 렌즈에 쉴드를 추가적으로 설계 하였다. 또한 투사렌즈의 비구면 렌즈 설계를 통해 주광축에 서 LED 칩 위치가 벗어날수록 패턴에 왜곡이 발생하지 않는 설계를 반영하였고, 시뮬레이션을 통해 중앙에 위치한 LED 칩과 중앙에서 벗어나는 $\mathrm{LED}$ 칩을 점등하고 전방 $25 \mathrm{~m}$ 지 점에 리시버를 설치하여 패턴을 확인한 결과 왜곡이 발생하 지 않는 동일한 패턴을 만족하였다.

\section{2. 조명 광학계 설계}

조명 광학계는 LED 앞 단에 2차렌즈 설계와 측벽 설계를 동시에 진행하였다. 2차렌즈는 광 효율을 높여주면서 사각 패턴을 형성한다. 또한 셀 간의 암영대를 최소화하여 패턴의 조도 균일도(Uniformity)를 향상시켜주는 역할을 한다. 그리 고 2차렌즈를 둘러싸고 있는 측벽은 LED 칩 간의 빛을 차단 해준다. 셀의 구성으로 패턴을 구현하는 매트릭스 빔 패턴의 경우 서로 광 경로의 영향을 주게 된다면 하나의 LED 소등 시 패턴간의 밝기 차이가 발생한다.

그림 7은 1차적으로 설계된 2차렌즈, 측벽 설계와 최적화 렌즈 설계를 동시에 보여준다. 그림 7(a)의 2차렌즈 설계의 경우, 광원의 입사 면을 오목으로 설정하여 빛을 최대로 퍼 뜨려 파라볼라 형태의 옆면을 맞고 평행광선으로 진행하는 원리와 사각형의 출사면을 통해 사각 패턴을 형성할 수 있도 록 설계하였다. 그리고 최종적으로 2 차렌즈의 옆면의 각도를 $10^{\circ}$ 로 최적화하여 빛을 최대한 모아 광 효율을 높였으며, 렌

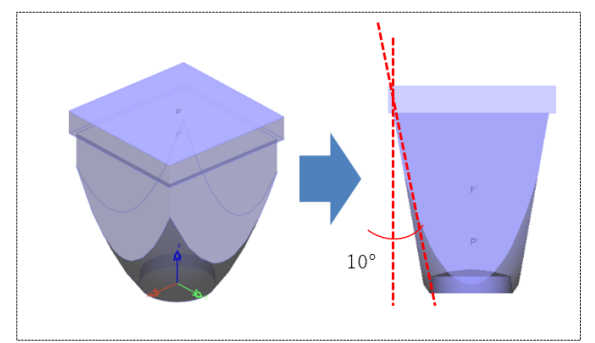

(a) Secondary Lens Design

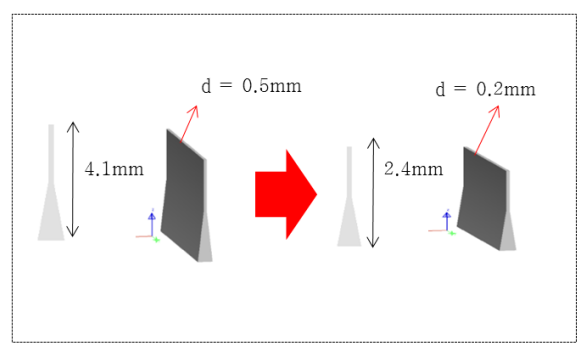

(b) Side Wall Design

FIG. 7. Secondary optics design and wall design of illumination optical system.
즈의 재질은 실리콘을 사용하였다. 또한 그림 7(b)의 측벽 설 계는 2 차렌즈 전체를 둘러싸는 깔때기 모양으로 1 차 설계를 진행하였으나 가공적인 문제를 고려하여 2차적으로 렌즈 사 이의 Air gap을 $0.2 \mathrm{~mm}$ 로, 측벽의 높이는 $4.1 \mathrm{~mm}$ 에서 2.4 $\mathrm{mm}$ 로 최적화를 실시하였다. 설계된 광학계의 시뮬레이션을 통해 조명광학계를 적용하기 전·후를 비교한 결과 조명 광 학계를 적용한 패턴 사이의 암영대가 최소화되어 조도 균일 도가 향상되는 것을 확인하였다.

\section{3. 통합형 광학계 분석}

상향등, $\mathrm{ADB}$ 패턴 구현을 위한 통합형 광학계의 구조는 다수의 $\mathrm{LED}$, 다수의 투사렌즈, 2 차렌즈, 측벽으로 구성된다. 그림 8은 베럴로 둘러싸인 통합형 광학계의 최종 형상과 세 부적으로 설계된 2차렌즈와 투사렌즈를 나타내었다. 통합형 광학계는 투사렌즈와 2차렌즈를 포함하며, 총 4장의 렌즈로 구성되어 있으며 그림에서 쉬운 이해를 돕기 위해 광원에서 가까운 순서대로 렌즈를 번호로 표기하였다. 전체적인 광학 계는 베럴로 둘러싸여 있으므로 자동차의 외부 충격으로부 터 렌즈를 보호하면서 고정시키는 역할을 한다.

실제 상황에서 상향등 구현 시 원거리 시인성을 확보하기 위해서는 패턴의 최대 $\mathrm{cd}$ 값이 $42000 \mathrm{~cd}$ 이상을 만족해야 한 다. 그림 9는 상향등과 $\mathrm{ADB}$ 패턴에 대한 분석 결과를 보여

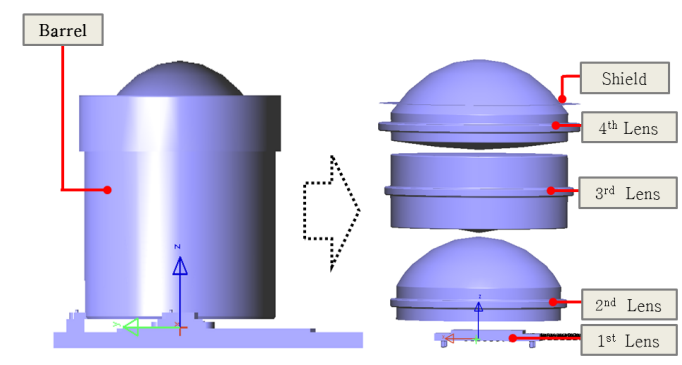

FIG. 8. Total optical composition.

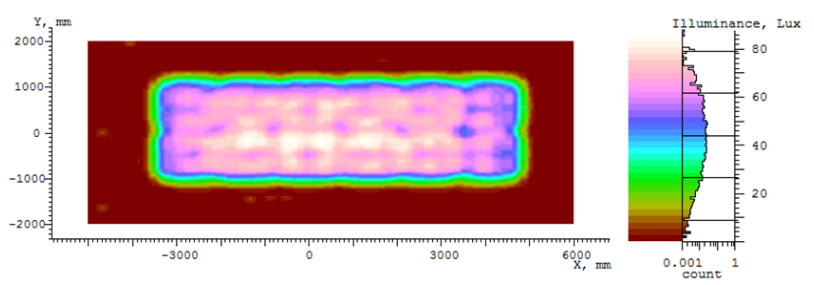

(a) Simulation Result of High Beam

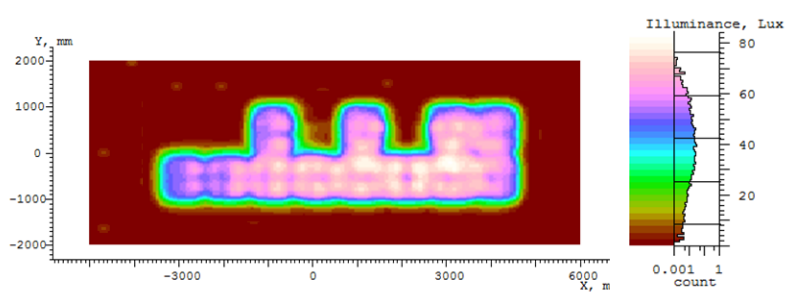

(b) Simulation Result of ADB

FIG. 9. Simulation result of high beam pattern and ADB pattern. 
주고 있다. 그림 9(a)는 설계된 광학계를 통해 상향등 패턴 구현을 위한 LED를 점등하고 LightTools 소프트웨어를 통해 시뮬레이션을 실시한 결과이며, 광도 값을 확인한 결과 약 $50000 \mathrm{~cd}$ 로 요구조건을 만족하는 광도 값을 얻었다. 그리고 그림 9(b) $\mathrm{ADB}$ 패턴의 경우에는 전방 차량의 눈부심 방지를 위해 LED 칩 소등 시 암영대 패턴 구현이 가능하고, 전방 $25 \mathrm{~m}$ 에서 $0.4 \mathrm{~lx}$ 이하를 만족해야 한다. 상향등과 동일한 소 프트웨어를 통해 시뮬레이션을 실시하였으며, 상향등 패턴에 서 추가적으로 $\mathrm{LED}$ 를 소등하고 시뮬레이션을 실시하였다. 그 결과 LED 소등 영역의 암영대가 뚜렷하게 형성되는 것을 확인하였다.

\section{IV. 제작 및 성능평가}

설계된 광학계로 시제품을 제작하였으며, 그림 10 은 실제 로 제작된 광학계를 통해 전방 $25 \mathrm{~m}$ 스크린에 상향등과 $\mathrm{ADB}$ 패턴을 점등하여 테스트한 결과이다. 그리고 표 2는 광 학계의 요구 조건과 실제로 제작된 광학계의 성능평가 결과 를 비교하였다. 그 결과 모든 셀 사이즈를 $2.5^{\circ} \times 2.5^{\circ}$ 로 설계 요구 조건에 만족하는 결과를 얻었다. 또한 배광 법규에 만 족하는 상향등의 원거리 시인성을 위한 패턴의 최대 $\mathrm{cd}$ 값이 $50000 \mathrm{~cd}$ 로 측정되었고, $\mathrm{ADB}$ 패턴 구현 시 대항차와 선행 차 운전자의 눈부심 방지를 위한 LED 소등 영역이 $0.32 \mathrm{~lx}$ 로 $0.4 \mathrm{~lx}$ 이하의 설계 조건 값을 모두 만족하였다.

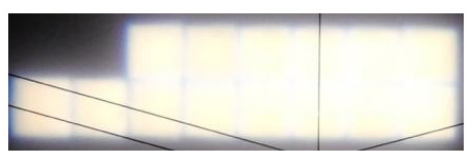

(a) High Beam Pattern

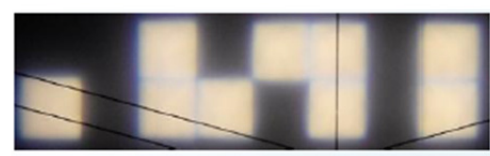

(b) ADB Pattern

FIG. 10. Real implementation of high beam and ADB.

TABLE 2. Measurement Result

\begin{tabular}{|c|c|c|}
\hline \multicolumn{2}{|c|}{ Optical Design Requirement } & Test Result \\
\hline $\begin{array}{l}\text { Total Pattern Size } \\
\text { (Lens axis: } 3 \text { ) }\end{array}$ & $16.25^{\circ} \times 5^{\circ}$ & $16.25^{\circ} \times 5^{\circ}$ \\
\hline $\begin{array}{l}\text { Pattern Size Of } \\
\text { Individual Chip }\end{array}$ & (1 Chip) $2.5^{\circ} \times 2.5^{\circ}$ & (1 Chip) $2.5^{\circ} \times 2.5^{\circ}$ \\
\hline High Beam Max cd & $>45000 \mathrm{~cd} @ 25$ m & $50000 \mathrm{~cd} @ 25 \mathrm{~m}$ \\
\hline Dark zone Lux & $\begin{array}{c}<0.4 \mathrm{~lx}(250 \mathrm{~cd}) \\
\text { @ } 25 \mathrm{~m}\end{array}$ & $\begin{array}{c}0.32 \mathrm{~lx}(200 \mathrm{~cd}) \\
\text { @ } 25 \mathrm{~m}\end{array}$ \\
\hline
\end{tabular}

\section{V. 결 론}

본 논문에서는 자동차의 지능형 전조등의 신기술인 Multi-array LED를 이용한 광학계의 설계를 실시하였다. 기 존의 다양한 빔 패턴을 구현하기 위한 추가적인 기계 장치가 필요한 기술과는 다르게 Multi-array LED를 이용한 지능형 전조등은 광원의 나열과 하나의 광학계 모듈로 다양한 패턴 을 광원의 점·소등으로 변화할 수 있으며 추가적인 기계 장 치를 필요로 하지 않는다. 설계된 통합형 광학계의 구성은 2 차렌즈, 측벽, 투사렌즈로 구성되며, 광학계 설계의 시뮬레이 션을 통해 빔 패턴을 만족하였다. 그리고 설계된 광학계의 제작 및 측정을 통해 상향등 구현 시 최대 $50000 \mathrm{~cd}$ 와 $\mathrm{ADB}$ 패턴 구현 시 광원의 소등 영역이 $0.32 \mathrm{~lx}$ 로 만족되어 배광 법규를 모두 충족하였다. 현재 상향등과 $\mathrm{ADB}$ 패턴뿐만 아 니라 AFLS, SPOT LIGHT 등과 같은 다양한 빔 패턴까지 구 현할 수 있는 광학계의 설계와 셀 사이의 발생하는 암영대를 최소화하기 위한 연구가 계속해서 진행되고 있다. 차량용 전 조등은 단순화와 지능화뿐만 아니라 운전자의 안전성과 시 인성까지 고려되어지는 추세로 개발이 활발하게 이루어지고 있으며, 점차 전조등의 광학계 범위도 넓어질 것으로 예상된다.

\section{감사의 글}

본 연구는 한국산업기술평가관리원의 지원으로 수행되었 습니다.

\section{References}

1. C. M. Lee, T. Y. Lim, J. W. Min, J. C. Lim, O. H. An, H. J. Kim, and H. Kim, "A study on the discomfortable feeling's appraisals of driver for the instant brightness fluctuation of the vehicle's headlamps," KIIEE 2007, 17-21 (2007).

2. K. S. Park and B. D. Kang, "The new technology trend of vehicle safety," KSCE 53, 126-136 (2005).

3. B. D. Park, "The technology trend of automobile headlamp," J. of KSAE 28, 82-87 (2006).

4. D. H. Park and J. K. Yang, "Trend of a design technology for lighting LED," KIEEME 22, 18-25 (2009).

5. B. D. Kang, K. S. Park, H. S. Lee, and H. G. Kim, "Performance evaluations of led headlamps," J. of KSAE 11, 737-742 (2010).

6. T. Targosinski, "Adaptive driving beam-new concept of vehicle front-light," J. of KONES 17, 455-458 (2010).

7. Hella Corporation, "Lighting technology," Lippstadt Germany, 6-11 (1995).

8. M. Götz and M. Kleinkes, "Headlamps for light based driving assistance," Proc. SPIE 7003, 70032B-1 70032B-10 (2008).

9. T. W. Lee and I. H. Park, "The introduction to the automotive headlamp using DMD,” J. of KSAE 33, 21-25 (2011). 
10. A. Cvetkovic, O. Dross, J. Chaves, P. Benitez, J. C. Minano, and R. Mohedano, "Etendue-preserving mixing and projection optics for high-luminance LEDs, applied to automotive headlamps," Opt. Express 14, 13014-13020 (2006). 